\title{
D iagnosis of Some Diseases in Medicine via computerized Experts System
}

\author{
R.A. Soltan ${ }^{1}$, M. Z. Rashad ${ }^{2}$, B.El-Desouky ${ }^{3}$ \\ ${ }^{1}$ Dep. of statistic and computer science,Faculty of science, Mansoura University \\ ${ }^{2}$ Dep. of Comp. scienecs, Faculty of Comp. and Info., Mansoura University, Egypt \\ ${ }^{3}$ Dep. of Mathematics, Faculty of Sciences, Mansoura University, Egypt
}

\begin{abstract}
Nowadays medical application especially diagnosis of some heart diseases has been rapidly increased because its importance and effectiveness to detect diseases and classify patients. In this research, we present the design of an expert system that aims to provide the patient with background for suitable diagnosis and treatment (Especially Angina Pectoris and Myocardial infarction). The proposed methodology is composed of four stages. The first stage is receiving the symptoms from the patient. The second stage is requesting from the patient to make some analysis and investigation to help the system to make a correct decision in the diagnosis. The third stage is doing diagnosis of patient according to information from patient (symptoms, analysis and investigation). The four stage is determining the name of appropriate medication or what should be done until the patient recovers (step therapy), so this system is able to give appropriate diagnosis and treatment for two heart diseases namely; angina pectoris and infarction. There are several programs used for diagnosis and system analysis, such as CLIPS and PROLOG. A medical expert system in this search made by Visual Prolog 7.3 is proposed.
\end{abstract}

\section{GENERAL TERMS}

Experts System, Diagnosis, medical, coronary artery diseases

\section{KEYWORDS}

Experts System, Diagnosis, medical, CLIPS, PROLOG, coronary artery diseases

\section{INTRODUCTION}

Increasing computer-based methods improve the quality of medical services. Artificial Intelligence (AI) is the area of computer science focusing on creating machines that can engage on behaviors that humans consider intelligent [1]. One of the most important areas of Artificial Intelligence (AI) is an Expert system. The proposed system for dealing with the problem of heart diseases diagnosis and treatment is an expert system. Expert System (ES) is widely used in many areas and it has many applications. Most important fields area of expert system is the medicine and it use in detection, diagnosing symptoms and treatment diseases. The user can interact with a computer to solve a certain problem by expert system. This is because the expert system can store heuristic knowledge. The development of expert system is implemented in visual prolog v7.3 programming environment [2]. These programming tools facilitate human knowledge or expertise for medical therapy. The reason for Visual prolog program is the flexibility the expandability and low lost. This helps medical expert (doctor) diagnosis of a patient rightly. The Coronary Artery Diseases consist of a lot of Diseases that have common symptoms. Some of them have similar symptom that make very difficult even for Cardiologist (specialist) to put a right diagnosis. This Expert System 
can do that. Diagnosis of Ischemic heart diseases is initially based on the symptoms that the person is suffering and the result of investigation. Many cases of heart diseases can lead to death. However, if detected early enough, the heart can be saved [3]. In this paper, we will introduce a system for diagnosis human heart diseases and treatment using visual prolog V 7.3.

We present in section 2 is previous work showing Expert system and medical data, section 3 shows the function of the proposed system. Section 4 shows Building diagnosis expert system using visual prolog V 7.3.

\section{STATE-OF-ART}

An expert system (ES) known as knowledge based system, is a computer program that uses knowledge and inference procedures to solve problems that are ordinarily solved through human expertise. The main components of an ES are: a) knowledge base, b) inference engine, c) userinterface.

There are many applications of expert systems such as diagnosis, design, planning, financial decision making etc. Most applications of expert systems in medicine involve predicting, diagnosing and treating a particular disease [4]. Now expert systems has many other roles in clinical care such as disease prevention, therapy, rehabilitation of the patient after therapy etc. $n$ medicine, expert systems are used to train the medical students on various medical tasks. In certain situations, where either the case is quite complex or there is no medical experts readily available for patients medical expert systems are useful. From the very beginning the main obstacle of using expert systems in medicine has been the accuracy of such systems [5]. The development of an expert system requires medical data of specialized doctor. This data is collected in two phases. Firstly, the creation of personal interview between doctor and patient record the medical background of heart disease. Secondly, medical data is turned into rules (IFTHEN). Rules for diagnosis contain in IF part the symptoms and in THEN part the disease. Rules for treatment contain in IF part the disease and in THEN part the treatment. The inference engine (forward reasoning) is the mechanism through which rules are selected to be fired. It is based on a pattern matching algorithm whose main purpose is to associate the facts (input data) with applicable rules form the rule base. Finally, the heart diseases are produced by the inference engine [6].

Coronary heart disease (CHD) is the most common form of heart disease and the single most important cause of premature death in certain parts of world. Disease of the coronary arteries is almost always due to sudden death. This research presents design of an expert system for diagnosis and treatment of coronary artery diseases namely ; angina pectoris and myocardial infarction.

1-Angina pectoris causes chest pain which is radiated to left shoulder, medial aspect of left arm , forearm and medial 2 fingers, its duration not $<2$ minutes and not $>20$ minutes precipitated by effort and relived by rest and sublingual nitrates ,associated with nausea, tachycardia vomiting, sweating and Hypertension. ESG at rest is normal, post do exercise ECG: stress test is depressed ST segment [7].

2-Myocardial infarction (MI) remains a leading cause of morbidity and mortality worldwide. Myocardial infarction occurs when myocardial ischemia, a diminished blood supply to the heart, exceeds a critical threshold and overwhelms myocardial cellular repair mechanisms designed to maintain normal operating function and homeostasis. ECG: Abnormal Q-waves "due to necrosis ", Raised ST segment or Depression and Inversion of T-wave [7]. 
International Journal of Computer Science \& Information Technology (IJCSIT) Vol 5, No 5, October 2013

Symptom diseases are classified into strong, moderate and mild as shown in table 1.This table shows clustering of symptom's facts to avoid repetition. We can use AND/OR to connect a premise clauses in compound rule as shown in fig 1

\begin{tabular}{l} 
If there symptom(s) Dyspnea (mild) \\
AND shock (mild) \\
AND weak in heart sound (mild) \\
AND chest pain (mild-moderate) \\
AND Gallop in heart sound (mild) \\
AND paradoxical splitting of $2^{\text {nd }}$ heart sound (mild) \\
AND BI.P(Hypertension) \\
AND pulse (Tachycardia) \\
AND Duration of pain (not $<20$ min and not $>20$ min) \\
OR fever (mild) \\
OR nausea (mild) \\
OR palpitation (mild) \\
$\quad$ THEN the Disease is Angina pectoris \\
\hline
\end{tabular}

Fig1.An example for production rule

But this information is not enough for Ischemic heart diseases diagnosis we need to do investigation also reach to correct diagnosis and then a correct treatment to ischemic heart diseases.

Table 1: Heart diseases symptom's clustering template

\begin{tabular}{|c|c|c|}
\hline $\begin{array}{l}\text { Symptoms } \\
\text { Disease }\end{array}$ & Angina pectoris & Infarction \\
\hline -Dyspnea & Mild & Strong(sever) \\
\hline -Shock & Mild & Strong \\
\hline -Weak in heart & Mild & Strong \\
\hline & Mild & Strong \\
\hline $\begin{array}{r}\text {-Gallop in heart } \\
\text { sound }\end{array}$ & Mild & \\
\hline $\begin{array}{r}\text {-Paradoxical } \\
\text { splitting of } 2^{\text {nd }} \\
\text { heart sound }\end{array}$ & 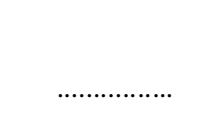 & Mild \\
\hline $\begin{array}{l}\text {-Paradoxical } \\
\text { splitting of } 4^{\text {th }} \\
\text { heart sound }\end{array}$ & ....... & Mild \\
\hline Pericardial rub- & Hypertension & Hypertension \\
\hline -BI-P & Tachycardia & Tachycardia \\
\hline \multirow[t]{2}{*}{-Pulse } & Mild-moderate & Strong \\
\hline & Mild & Strong \\
\hline
\end{tabular}


International Journal of Computer Science \& Information Technology (IJCSIT) Vol 5, No 5, October 2013

\begin{tabular}{|r|c|c|}
\hline Chest pain - & Mild & Strong \\
-Palpitation & Mild & Strong \\
Fever- & $\begin{array}{c}\text { Not }>20 \mathrm{~min} \text { and } \\
<20 \mathrm{~min}\end{array}$ & $>20 \mathrm{~min}$ \\
-Nausea & & \\
-Duration of pain & & \\
\hline
\end{tabular}

Table2. Ischemic heart diseases to Investigation (ECG at rest)

\begin{tabular}{|l|l|l|l|l|}
\hline ECG & Normal & Ischemia & $\begin{array}{l}\text { Angina } \\
\text { pectoris }\end{array}$ & Infarction \\
\hline Normal & T & F & F & F \\
\hline $\begin{array}{l}\text { Change in T- } \\
\text { wave and ST } \\
\text { segment }\end{array}$ & F & T & F & F \\
\hline $\begin{array}{l}\text { Depressed ST } \\
\text { segment }\end{array}$ & F & F & T & F \\
\hline $\begin{array}{l}\text { Deep Q-wave } \\
\text { and elevated } \\
\text { ST segment }\end{array}$ & F & F & F & T \\
\hline
\end{tabular}

Table3. Ischemic heart diseases to Investigation (ECG at stress):

\begin{tabular}{|l|l|l|l|l|}
\hline ECG & Normal & Ischemia & $\begin{array}{l}\text { Angina } \\
\text { pectoris }\end{array}$ & Infarction \\
\hline Normal & T & F & F & F \\
\hline $\begin{array}{l}\text { Change in } \\
\text { T-wave F } \\
\text { and ST } \\
\text { segment }\end{array}$ & T & F & F \\
\hline $\begin{array}{l}\text { Depressed } \\
\text { ST } \\
\text { segment }\end{array}$ & F & F & T & F \\
\hline $\begin{array}{l}\text { Deep Q- } \\
\text { wave and } \\
\text { elevated } \\
\text { ST } \\
\text { segment }\end{array}$ & & F & F & T \\
\hline
\end{tabular}

Table 4. Ischemic diseases to investigation (ECHO):

\begin{tabular}{|c|c|c|c|c|}
\hline ECHO & Normal & Ischemia & $\begin{array}{c}\text { Angina } \\
\text { pectoris }\end{array}$ & infarction \\
\hline Normal & $\mathrm{T}$ & $\mathrm{F}$ & $\mathrm{F}$ & $\mathrm{F}$ \\
\hline $\begin{array}{c}\text { Abnormal } \\
\text { motion of } \\
\text { cardiac } \\
\text { muscle }\end{array}$ & $\mathrm{F}$ & $\mathrm{T}$ & $\mathrm{F}$ & $\mathrm{F}$ \\
\hline akinsia & $\mathrm{F}$ & $\mathrm{F}$ & $\mathrm{F}$ & $\mathrm{T}$ \\
\hline
\end{tabular}


Investigation is classified into ECG (at rest), ECG (at stress), ECHO as shown in table 2.3,4.. We can use AND/OR to connect a premise clauses in compound rule as shown in fig 2

If there investigation (s) ECG(normal)
AND exercise EcG(change in T-wave and ST segment)
AND ECHO (Abnormal motion of cardiac muscle)
OR ECG (change in T-wave and ST segment)
\[ \text { THEN the Disease is Ischemia } \]

Fig2. an example for production rule

Table5. Determine type of Ischemia:

\begin{tabular}{|l|l|l|}
\hline Dinitra tab sublingual & Improve & Not improve \\
\hline After $1^{\text {st }}$ tab & Angina pectoris & Take $2^{\text {nd }}$ tab \\
\hline After $2^{\text {nd }}$ tab & Angina pectoris & Take $3^{\text {rd }}$ tab \\
\hline After $3^{\text {rd }}$ tab & Angina pectoris & Infarction \\
\hline
\end{tabular}

We can use AND/OR to connect a premise clauses in compound rule as shown in fig 3

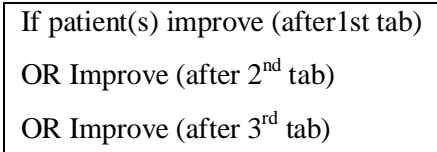

THEN The Disease is Angina pectoris

Fig3.An example for production rule

\section{PROPOSED FRAMEWORK}

\subsection{Flowcharts}

The proposed program is receiving the symptoms from patient for diagnosis and treatment of ischemic heart diseases by asking about: personal history, family history, symptoms, signs and then requires doing investigation to give a correct diagnosis.

First, let us present the Algorithm for ischemic heart diseases to investigation 
International Journal of Computer Science \& Information Technology (IJCSIT) Vol 5, No 5, October 2013

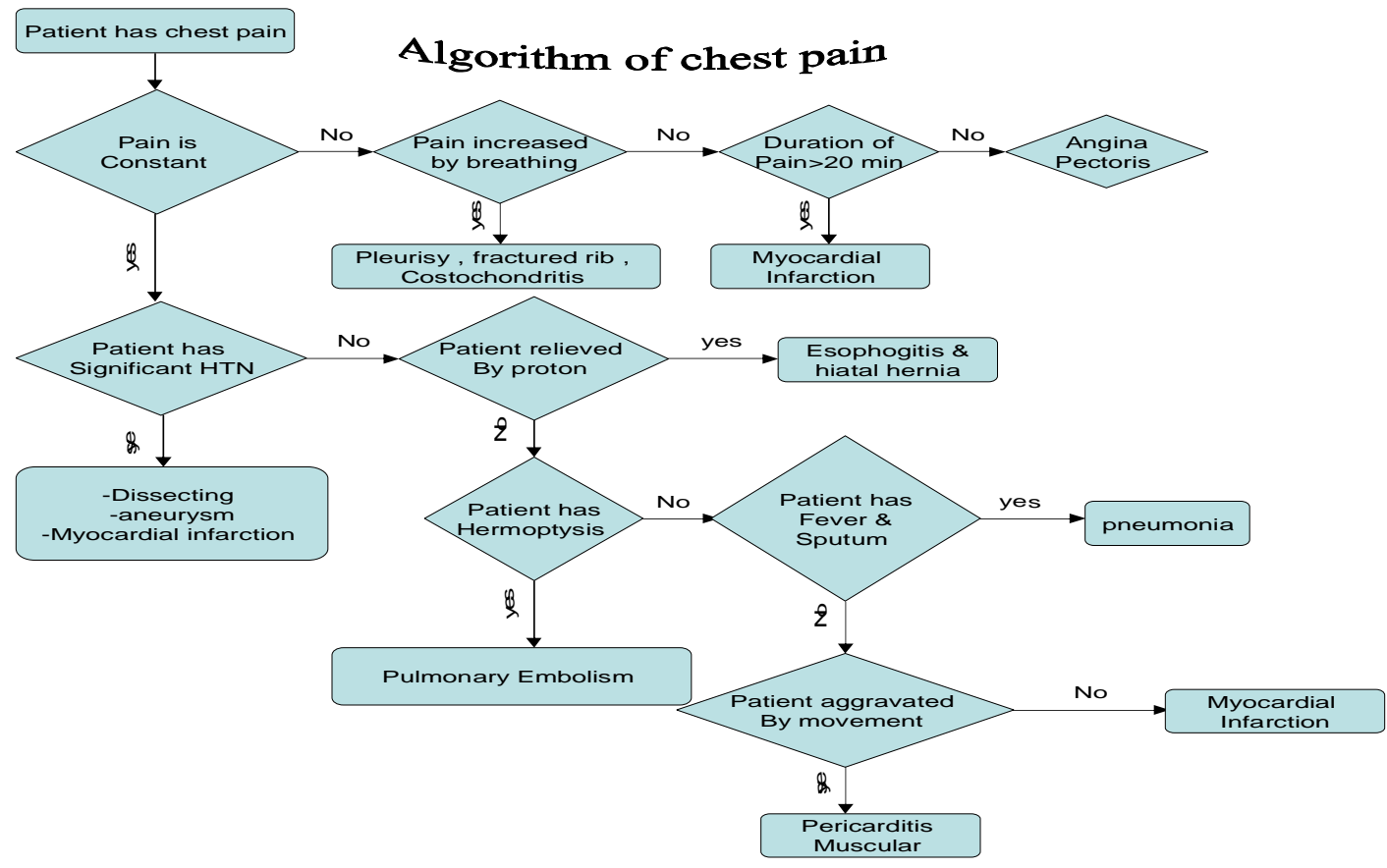

Fig 4.chest pain flowchart

Here is the Algorithm for ischemic heart diseases to investigation:

Algorithm of investigation

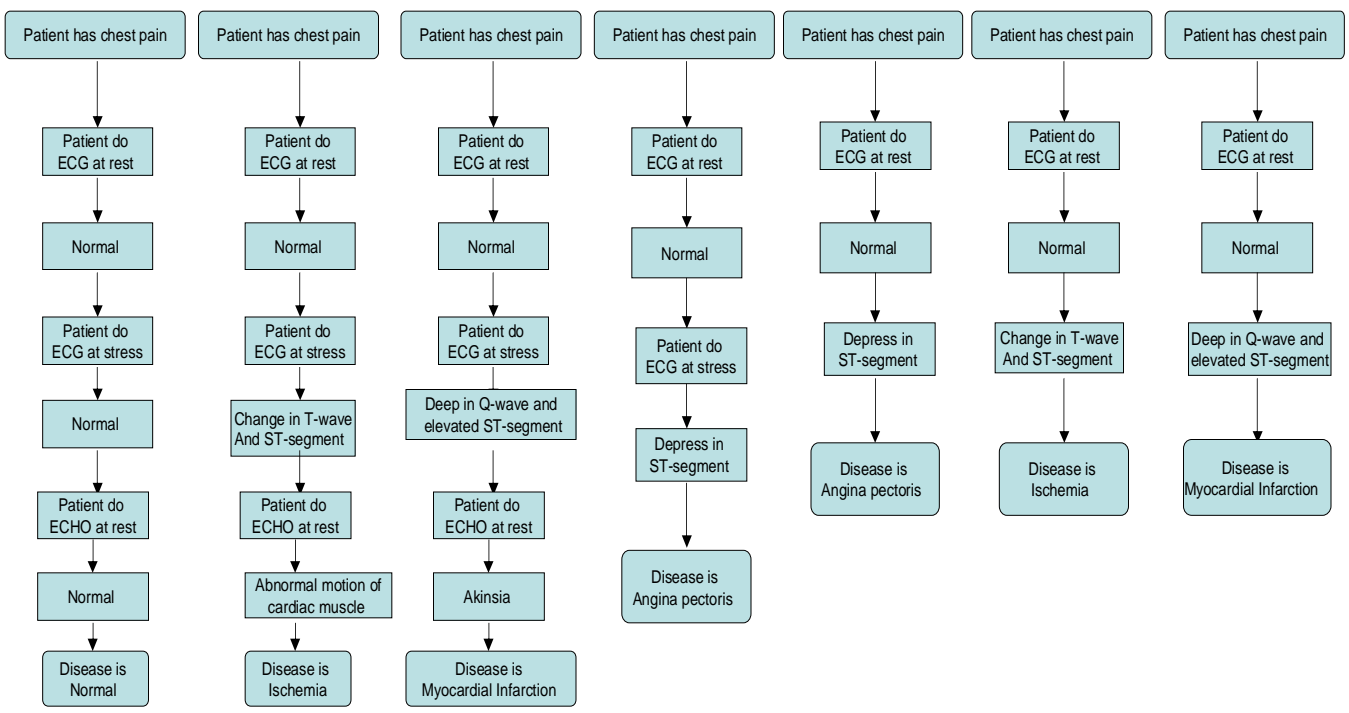

Fig5.investigation flowchart

Here is the Algorithm for ischemic heart diseases to ischemia: 
International Journal of Computer Science \& Information Technology (IJCSIT) Vol 5, No 5, October 2013

Algorithm of Ischemite

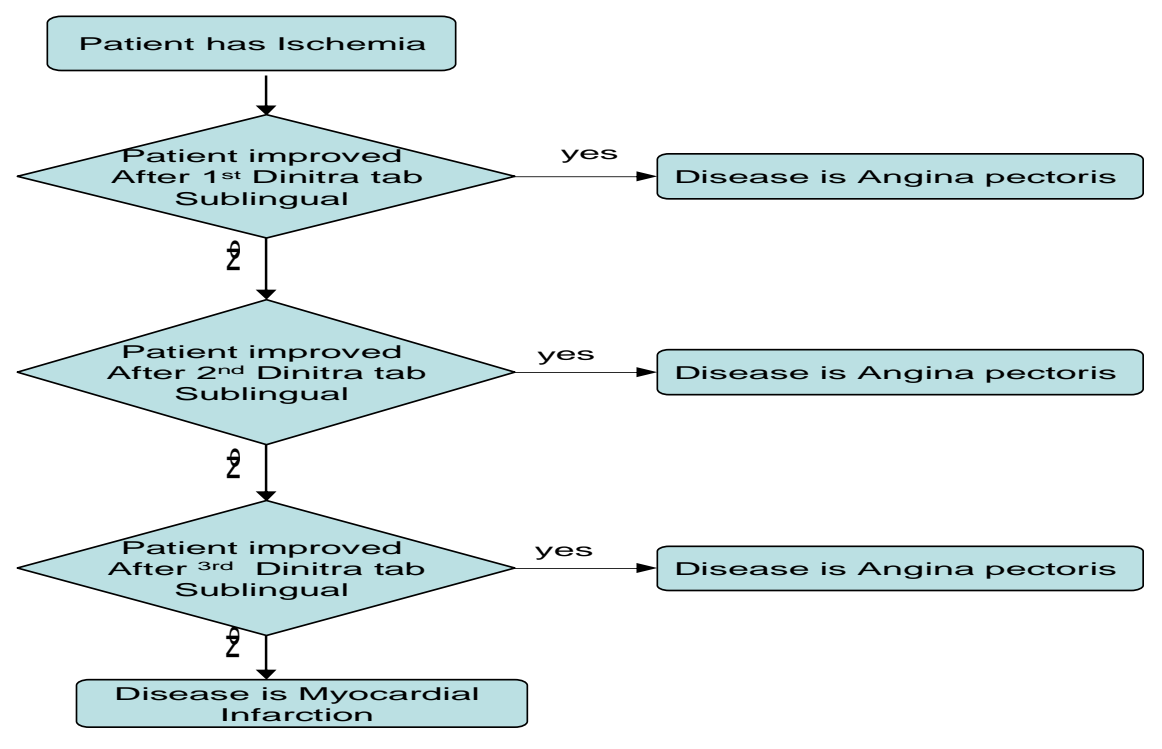

Fig 6. ischemia flowchart

This rules discussed the diagnosis of Ischemic heart diseases (angina pectoris and myocardial infarction) by do investigation to get actually diagnosis to patient and then treatment. We will present the rule for ischemic heart diseases to Treatment

fig 7 shows the description of the rules for treatment of coronary artery diseases:

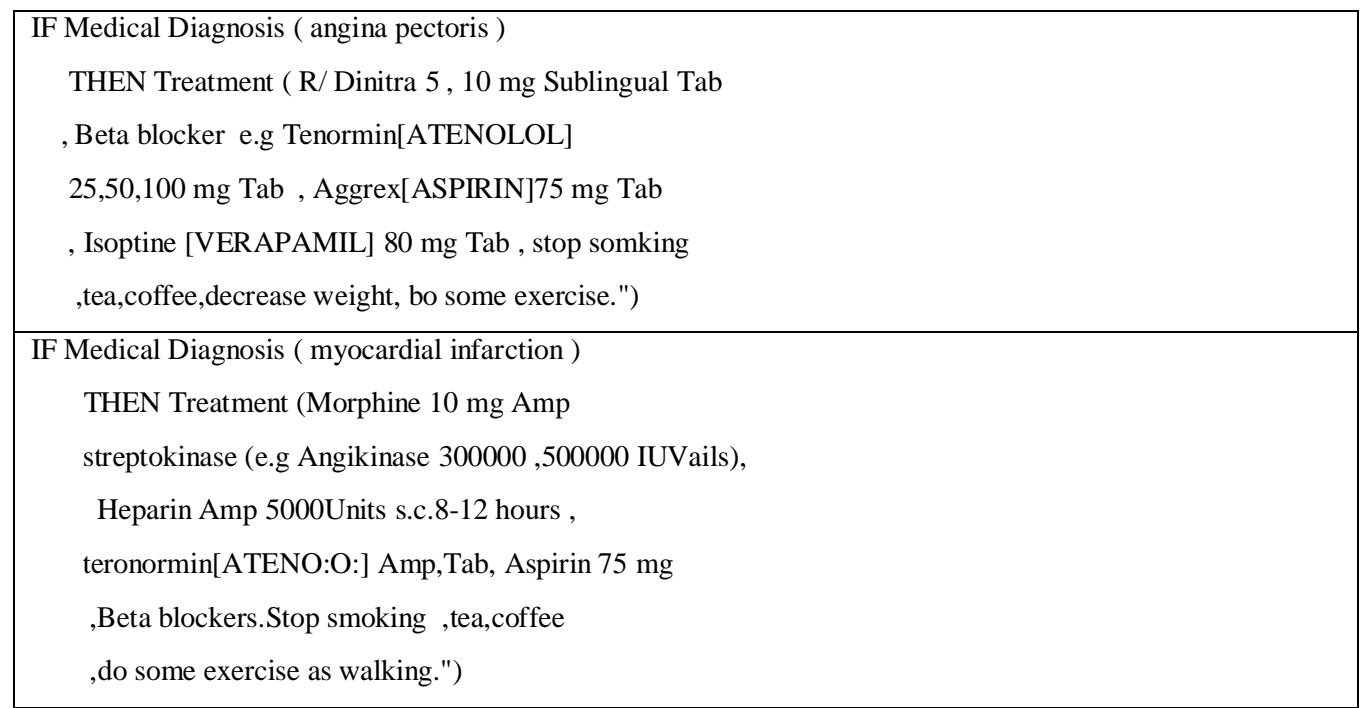

Fig 7. treatment of Infarction

The description of the rules generated by using PROLOG PROGRAM: 
Rule 1

Treatment( R/ Dinitra 5, $10 \mathrm{mg}$ Sublingual Tab

, Beta blocker e.g Tenormin[ATENOLOL]

25,50,100 mg Tab , Aggrex[ASPIRIN]75 mg Tab

, Isoptine [VERAPAMIL] $80 \mathrm{mg}$ Tab , stop somking

,tea,coffee,decrease weight, bo some exercise."):-Medical

Diagnosis(angina pectoris)

Rule 2

Treatment(R/Morphine 10 mg Amp ,streptokinase

(e.g Angikinase 300000,500000 IUVails),

Heparin Amp 5000Units s.c.8-12 hours , teronormin[ATENO:O:] Amp,Tab, Aspirin 75 mg

,Beta blockers.Stop smoking ,tea,coffee

, do some exercise as walking."):-Medical

Diagnosis (myocardial infarction)

We will use this code and the previous rules in visual prolog to design graphical user interface that help the user to connect with system. The user interface is represented as menu which displays the ischemic heart diseases (angina pectoris and myocardial infarction) to the user. A main window displays the steps; the user should do to get a correct diagnosis and treatment when the system starts.

\subsection{User Interface}

Figures 7, 19 show project main screen. Figures 8, 9, 10, 11,12and 13, 14, 15 show the system input patient data screens for heart diagnosis. The system asks a doctor (user) about the demographic data concerns information such as patient; age, sex cardiology risk factors, clinical data symptoms and signs through different dialogues and store answer in its knowledge base. Figures 16, 17 show the system input patient investigation screens for heart diagnosis. After finishing the questions concerning the symptoms dialogue, the results appear as shown in fig 18 . After determining type diseases, the treatment appear as shown in fig 20.

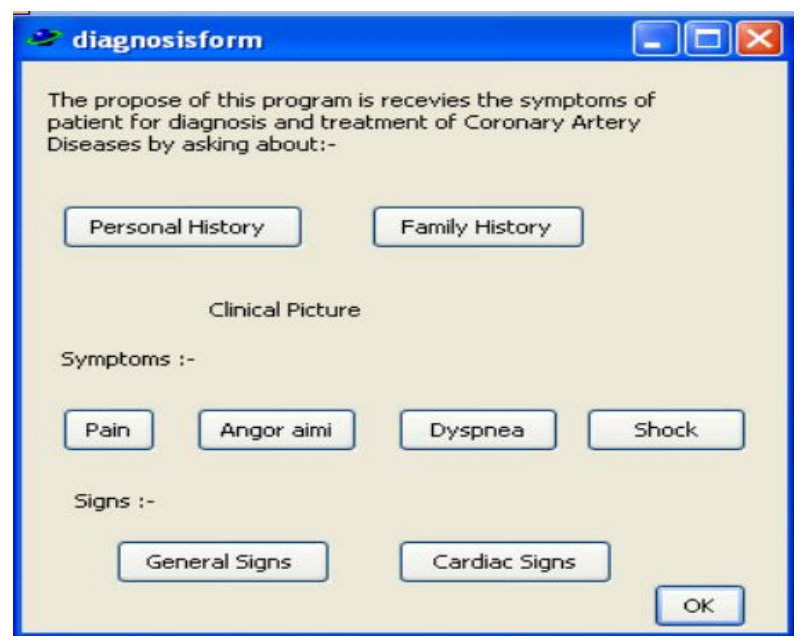

Fig.7. Main screen for diagnosis 
International Journal of Computer Science \& Information Technology (IJCSIT) Vol 5, No 5, October 2013

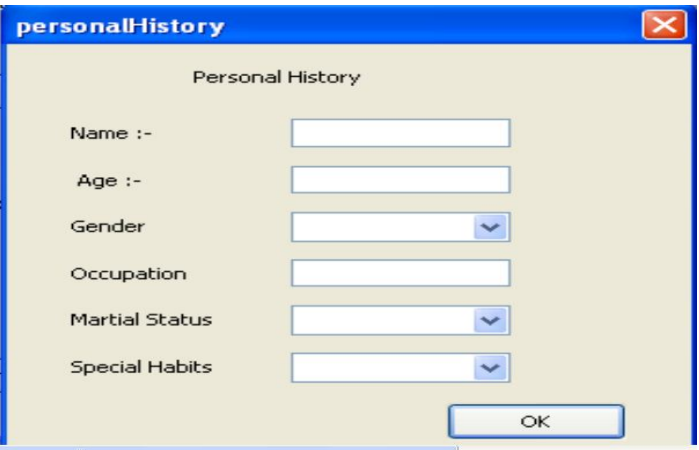

Fig .8. Input data for heart diagnosis $1^{\text {st }}$ screen.

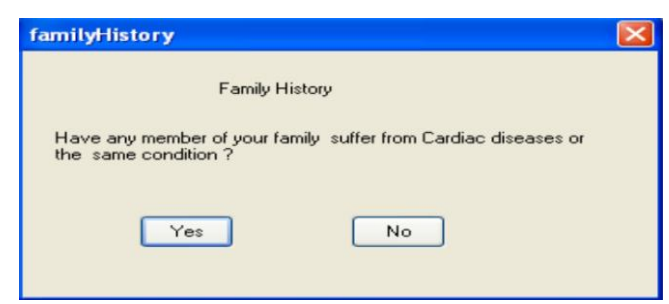

Fig. 9. Input data for heart diagnosis $2^{\text {nd }}$ screen.

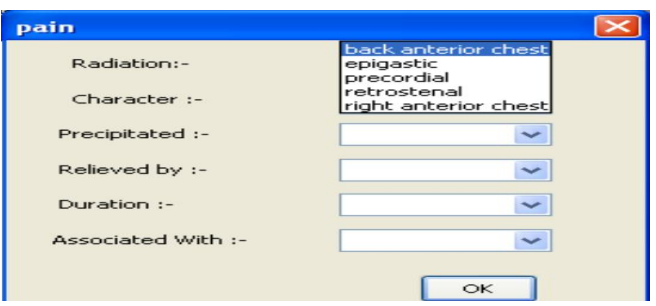

Fig. 10. Input data for heart diagnosis $3^{\text {rd }}$ screen.

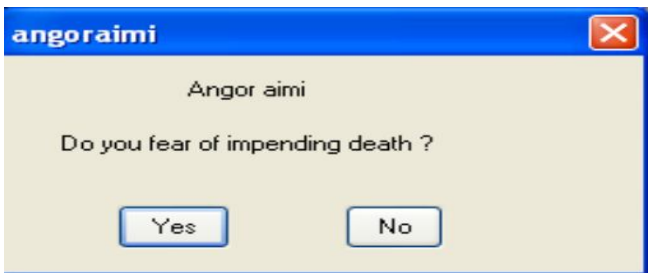

Fig. 11. Input data for heart diagnosis $4^{\text {th }}$ screen.

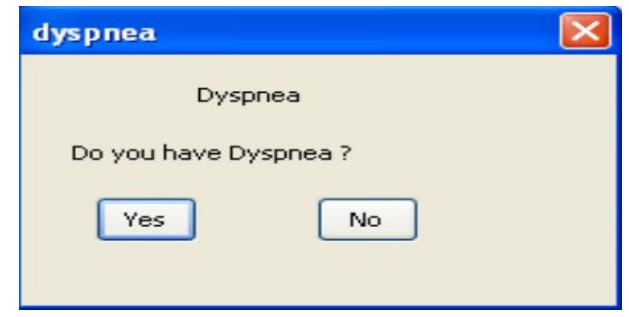

Fig. 12. Input data for heart diagnosis $5^{\text {th }}$ screen. 
International Journal of Computer Science \& Information Technology (IJCSIT) Vol 5, No 5, October 2013

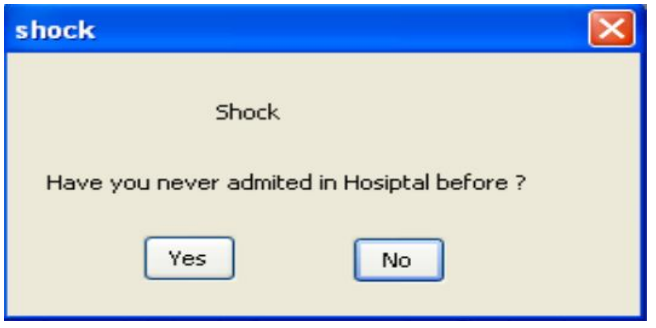

Fig. 13. Input data for heart diagnosis $6^{\text {th }}$ screen.

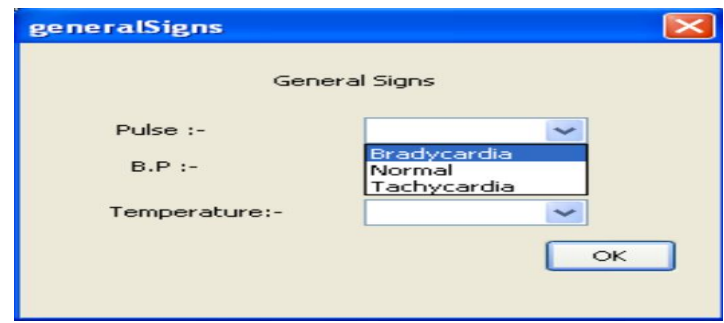

Fig. 14. Input data for heart diagnosis $7^{\text {th }}$ screen.

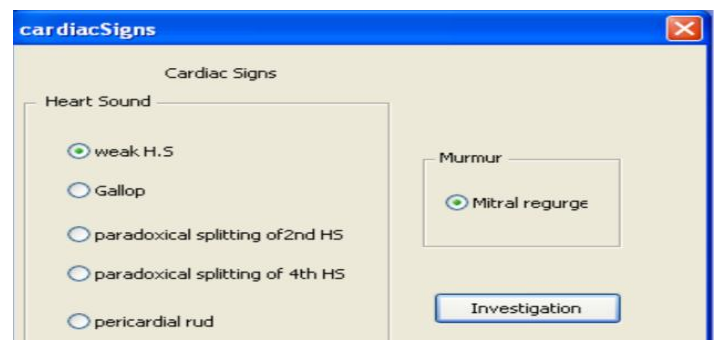

Fig. 15. Input data for heart diagnosis $8^{\text {th }}$ screen.

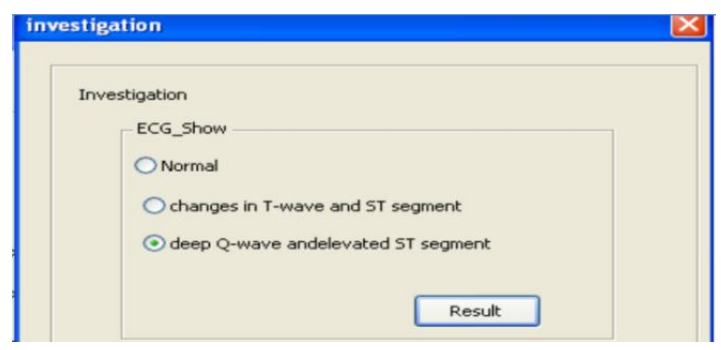

Fig. 16. Input investigation for heart diagnosis $1^{\text {st }}$ screen.

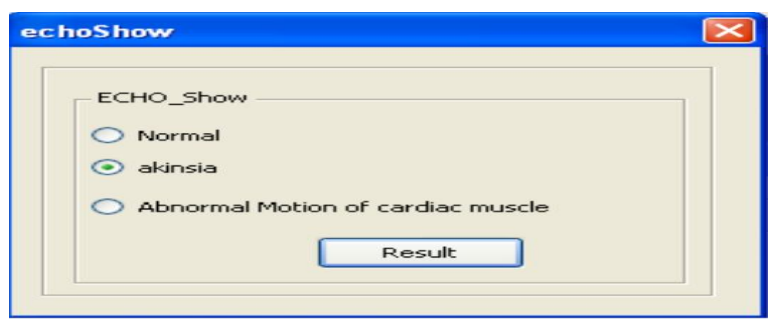

Fig. 17. Input investigation for heart diagnosis $2^{\text {nd }}$ screen. 


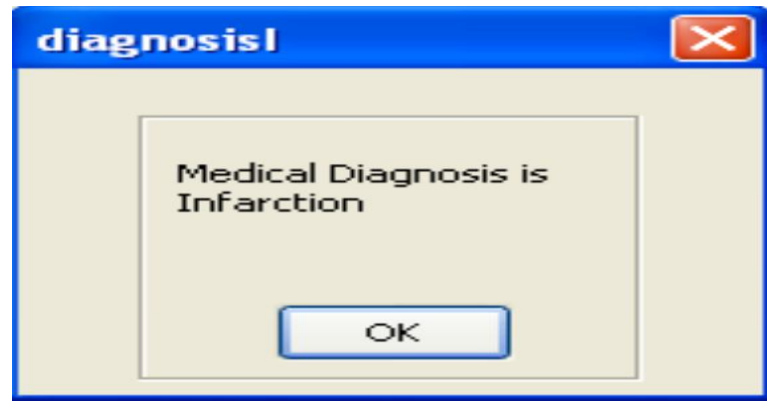

Fig. 18. Output heart diagnosis results screen.

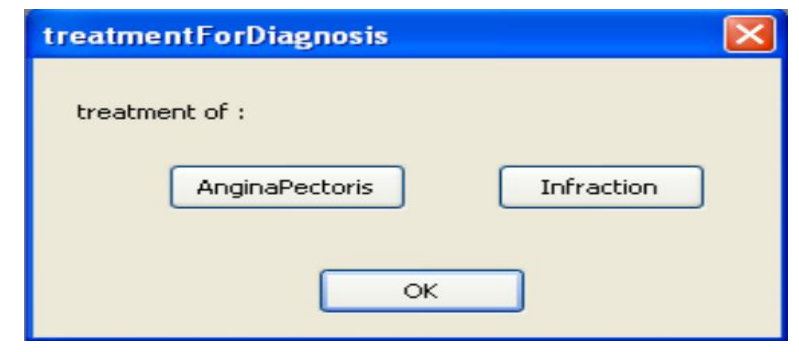

Fig.19, Main screen for diagnosis.

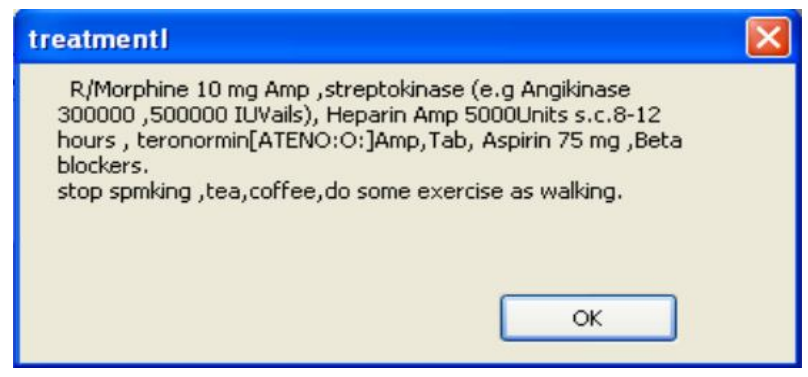

Fig. 20, Output heart treatment results screen.

\section{CONCLUSION}

The expert systems have an interesting application. In addition, ES has created considerable importance systems of diagnosis. Doctors and patients get help from the propose system .ES provides decision support system, Interactive training tool and expert advice .The system displays diagnosis of heart disease using intelligent system. The proposed system is essentially a production a production rule system (i.e., composed of IF-THEN) used conjunction with uncertainty reasoning. In the next research we will explain how to design Graphical user interface by using previous rules in visual prolog version 7.3 and how turning on the program by user.

This paper described a prototype model of a expert system for diagnosing and treatment heart diseases. The system uses the rule-based reasoning technique through simple querying of symptoms, signs and investigation done to the patient. The system can be used for diagnosing heart disease patient and then give treatment. 
International Journal of Computer Science \& Information Technology (IJCSIT) Vol 5, No 5, October 2013

\section{REFERENCES}

[1] Russell, S.andP.Norvig, 2002.Artifical Intelligence:Amordern Approach,prentice Hall,second Edition.

[2] Beverly G.Hope,Rosewary H.wild,"An Expert Support System for Service Quality Improvement",proceedings of the twenty-seventh Annual Hawaill International conference on system science, 1994.

[3] Turban E.,1992.ExpertSystem and Applied Artificial Intelligence, Mecmillan publishing company ,New York.

[4] Joseph C.Giarratano,Gary D.Riley,"Expert System Principles and Programming , Third Edition",pp.624,1998-02-09.

[5] Karagiannis S., Dounis A., Chalastras T., Tiropanis P., and Papachristos D., 2006,"Design of Expert System for Search Allergy and Selection of the Skin tests using clips, International Journal of Information Technology,3(1).

[6] Jackson , P.,1999,"Introduction Expert Systems, Harlow , England:Addison Wesley Longman . Third Eddition.

[7] Abdel Fattahh . Madkour, Magdah.Mohammed, "Superguide for Diagnosis and Treatment".

[8] Samy S.,Abu Naser, Abu Zaiter A.Ola:"An Expert System for Diagnosis Eye Diseases using Clips",Journal of Theoretical and Applied Information Technologh.

[9] http"//www.allaboutvision.com/conditions/droopinglisds.htm.

[10] http://www.umm.edu/ency/article/003033.htm.

[11] http://www.mothernature.com/library/Bookshelf/books/16/69.cfm.

[12] Azaabs.,Abu Naser S., and Sulisel O.,2000.Aproposed Expert Systems for selecting exploratory factor analysis procedures, Journal of the college of education,4(2):9-26.

[13] Alison Cawsey, Introductory AI course, available at http://www.macs.hw.ac.uk/ alison/ai3notes/all.html, accessed 30/12/07.

[14] Shu-Hsien L., 2005. "Expert Methodologies and application- adecade review form 1995 to 2004, Expert system with Applications,28:93-103.

[15] E.P.Ephzibah, School of Information Technology and Engineering, VTT University,Vellore,TamilNadu.India,"A Hybrid Genetic-Fuzzy Expert System for Effective Heart Disease Diagnosis". 